\title{
Design of Non-Full Irrigation Management Information System of Hebei Province Based on GIS
}

\author{
Junliang He, Yanxia Zheng, and Shuyuan Zhang \\ Department of Resource \& Environment, Shijiazhuang University, \\ Shijiazhuang 050035, China \\ hejunliang0927@163.com
}

\begin{abstract}
Combined the data of irrigation experiments in Hebei Province, The paper built an integrated system which integrates data input and output, management, analysis and decision. The system is based on GIS (Geographic Information System), DSS (Decision Support System) and crop water production formula. With the establishment of the system, the modern management level of non-full irrigation will be advanced, and the allocation of soil and water resources will be optimized. By analyzing the system demand, the framework of non-full irrigation management information system was proposed, and the main function of the system was designed in the article.
\end{abstract}

Keywords: Geographic Information System, Non-full Irrigation, Hebei.

\section{Introduction}

Water is the basic natural resources for social and economic development, and also the important strategic resources. With the low per capita water resources and uneven space-time distribution, the contradiction between supply and demand of water is still very prominent in our country. The annual amount of water shortage reaches 300-400 billion cubic meters in China which is one of the water shortage countries. Hebei is one of the serious water shortage provinces in China, the per capita water resources is oneeighth of the national average level. In this area, 90 percent of agricultural water is used for crop irrigation, but the actual utilization rate of water resources is only about 45 percent, lower than 50 percent which is the utilization rate of the most water shortage country. There exists a large water saving potential in Hebei Province behind the phenomenon of water shortage [1]. Therefore, the development of high efficiency and water saving agriculture is one of the main measures to alleviate water shortage, and to promote sustainable development of agriculture in this area.

As an advanced mode of water saving irrigation, the non-full irrigation is studied from various aspects in recent years. According to the analysis of water consumption of wheat in North China Plain, Changming Liu etc reveal wheat water effect and water requirement [2]. Based on the irrigation experimental data in Linxi and Wangdu, Shaoyuan Feng etc use multiple regression analysis method to determine the sensitive index of the model [3]. Combined irrigation experimental data in Wangdu, Luhua Yang etc discuss the solution method for two dimensional dynamic programming 
of the Jensen model [4]. According to the irrigation experimental data in Gaocheng, Wangdu and the central experiment stations, Zunlan Luo etc select Jensen, Minhas, Blank, Stewart and Singh models to analyze water production function of maize in Hebei Province [5]. At present, the information of non-full irrigation in this region is acquired and managed mainly by traditional manual work, the effective information management, maintenance, and sharing will be impossible to realize. To develop water saving agriculture, the key is to integrate irrigation experimental results and information technology, establish the decision support system of water saving irrigation, promote the modern management level of non-full Irrigation, and optimize the allocation of soil and water resources.

\section{General Structure Design}

Facing the decision making managers and professionals, the non-full irrigation information has spatial and temporal distribution properties. The information involves topography, hydrogeology, river system, weather, vegetation, soil and other factors in the agricultural area. The GIS has efficient ability of spatial data management, and flexible ability of comprehensive analysis. DSS can provide the decision support environment of model construction, process simulation, and effectiveness evaluation for the management [6]. Therefore, In view of the professional model, GIS and DSS technology, considering practicality and scalability, the system architecture based on $\mathrm{C} / \mathrm{S}$ mode is proposed. The system uses SQL Server which is a large relational database to manage the spatial data and non-spatial data, and adopts GIS software

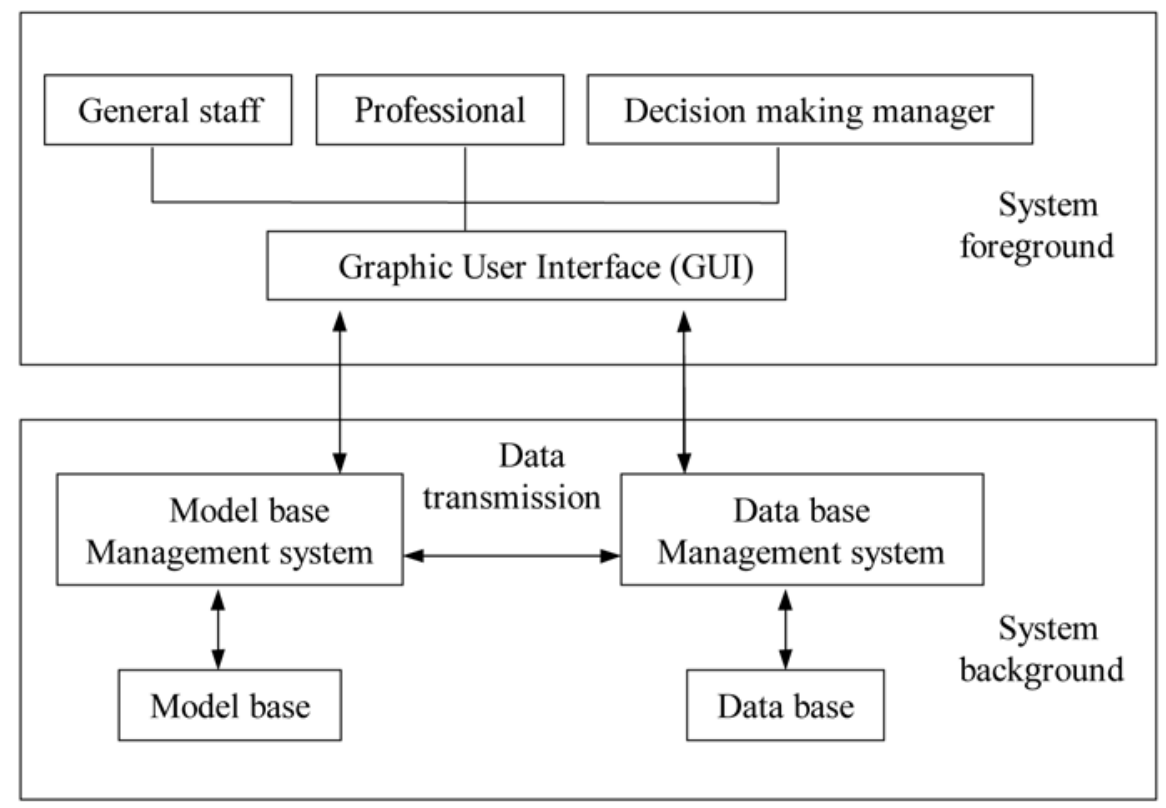

Fig. 1. The basic structure of non-full irrigation management information system 
development platform MAPGIS 7. 0and Microsoft Visual Basic 6.0 to develop. The basic framework of the system is shown in Figure 1.

\section{Database Design}

The main function of database system is to manage, store related information, and provide the support for the establishment and auxiliary management of the non-full irrigation schedule design. The database design is the basis for development application system, including irrigation information database and geographic information database two categories.

\subsection{Irrigation Comprehensive Information Database}

In this paper, according to the need of the non-full irrigation management, and combined the irrigation experimental data of agricultural experiment stations, the

Table 1. The content of agricultural irrigation comprehensive information database

\begin{tabular}{|c|c|}
\hline Data type & Data content \\
\hline $\begin{array}{l}\text { Basic } \\
\text { information of } \\
\text { irrigation station }\end{array}$ & $\begin{array}{l}\text { site code, site name, latitude, longitude, annual average } \\
\text { temperature, annual average evaporation, soil, field } \\
\text { moisture capacity, soil capacity, organic matter content, } \\
\text { total nitrogen, total potassium, total phosphorus, salt } \\
\text { content, groundwater depth, groundwater salinity etc }\end{array}$ \\
\hline $\begin{array}{c}\text { Irrigation } \\
\text { experimental data }\end{array}$ & $\begin{array}{l}\text { hydrometric station code, hydrometric station name, } \\
\text { crops name, growth stage name, beginning year, } \\
\text { beginning month, beginning date, ending year, ending } \\
\text { month, ending date, growth period day, precipitation, } \\
\text { survey month, survey date, soil humidity, irrigation } \\
\text { month, irrigation date, irrigation quota, water } \\
\text { consumption, yield, method etc }\end{array}$ \\
\hline \multicolumn{2}{|l|}{$\begin{array}{l}\text { Basic } \\
\text { information of } \\
\text { meteorological } \\
\text { station }\end{array}$} \\
\hline $\begin{array}{l}\text { Meteorological } \\
\text { monitoring data }\end{array}$ & $\begin{array}{l}\text { site code, site name, latitude, longitude, altitude, year, } \\
\text { month, day, time pressure, time temperature, time } \\
\text { relative humidity, time precipitation, time wind speed, } \\
\text { daily average sunshine time, daily extreme temperature, } \\
\text { minimum relative humidity etc }\end{array}$ \\
\hline Water bulletin & $\begin{array}{l}\text { surface water resources, groundwater resources, water } \\
\text { supply, water consumption, effective irrigated areas on } \\
\text { farmland etc }\end{array}$ \\
\hline
\end{tabular}


comprehensive information database is established, which includes irrigation data, meteorological data and water data etc (Table 1). At the same time, in order to realize the connection of the comprehensive information database and irrigation geographic information database, the shared field parameters are also taken into account in the database design phase.

\subsection{Geographic Information Database}

Geographical information database is the basis for the function realization of GIS. It mainly accomplishes graphic data management, retrieval and query, as well as the spatial analysis and evaluation of thematic data. Taking advantage of the vectorization function of Mapgis, the author obtained the administrative map of Hebei province (surface), the main water distribution (line), irrigation experiment stations distribution (points), weather station distribution (points) and so on. In order to connect with the database of irrigation comprehensive information, using the property management function of Mapgis, the author modified the geography information table on the digital map, and added the corresponding shared field parameters. In addition, the modify functions of geographical information database are not provided for ordinary users in order to prevent mistakes causing by modification in the geographical information database.

\section{Model Base Design}

According to the model of application analysis which is called during decision analysis, model base system presents data demand and storage format requirement to the database system. The optimization of the irrigation schedule model is the core of decision support system. In order to achieve high yield targets, under the limited irrigation quota conditions, the optimal allocation of the irrigation quota in timing and quantity is realized. Using the crop-water model (MCRW) as constraints or objective function, and the crop water consumption as the variable, the relation between the yield and the water deficit in different growth stage and different degree is revealed in this system. With the linear programming method, the optimal solution is obtained through the linear processing of the objective function, the calculating processing is simplified, and the optimization of the non-full irrigation schedule design is realized.

A series of professional models is established in this system, involving reference crop water requirements, crop water requirements, irrigation quota calculation and assessment of crop water deficit. Base on the analysis of the spatial and non spatial information, enlightened by the professional knowledge and experience, decisionmakers can evaluate and predict water supply and demand, and establish water saving irrigation strategies.

\section{Function Module Design}

\subsection{GIS General Functions}

Data management: With the data management platform of entire system, a series of operations are accomplished, such as daily management and maintenance of database, 
data edit, data import and data export. The function of the system includes database management, documentation management, data manipulation and metadata maintenance and so on.

Query and retrieval: Based on the function of the visual graphic display, with the aid of functions such as roaming, zooming and eagle-eye, the location, query and browsing for the spot, line, plane and other geographic features are realized. According to the combination of data item and any logical expression, users can query and retrieve the attribute data.

Statistical analysis: The system may carry on the statistical calculation to the related data, including maximum value, minimum value, average value, histogram computation and so on.

Special output: According to the need, users can choose the layer to output water supply and demand maps, agricultural weather information maps and other thematic maps, can also output all kinds of the irrigation resources parameters in the form of statistical charts and text statements, including known data and the result data.

\subsection{Professional Analysis Functions}

Analysis of crop water requirement: Based on the Penman formula, the crop water requirements at any day can be calculated, and the daily crop water requirements and the monthly crop water requirements from 1991 to 2000 in the experimental Station of Hebei Province can be queried. Using the reference crop evaporation quantity to calculate the crop evaporation quantity, the crop water requirements can be calculated. Based on the experimental data of crop water requirements, the query of the different crop coefficient in different region or during whole growth period can be realized. According to the soil condition, the irrigation quota before planting and the irrigation quota in each growth phase can be calculated.

Optimization of the irrigation schedule design: Using the existing analysis results of irrigation data, the crop - water model which suit for the different corps in different region of Hebei province, and the sensitive index in each growth phase can be queried. The irrigation quota, the crop water consumption corresponding the maximum yield treatment, the relative yield and the relative evaporation in each growth phase, the effective rainfall and other data can be set by users, also can be queried from the functional modules such as the basic information and analysis of crop water requirements. Through inputting the limited water supply (irrigation quota), the water allocation optimized strategy with different irrigation quota can be calculated, and the comparative analysis of the economic scale irrigation quota can be carried on, according to the relations between each kind of irrigation quota and optimal relative analog output.

\subsection{System Maintenance and Help Functions}

System login: In order to ensure the security of the system, users must input the user's name and the password to entry the system.

System help: The functions of system help include system description and user guide and so on. 


\section{Conclusion}

Combined GIS and professional models, with the development of the non-full irrigation management information system, the graph and the attribute data are queried reciprocally; the irrigation data and agricultural resource are managed scientifically. The partial interface of the system is shown in Figure 2. Based on this, according to the water resources condition in different region and the different crop water deficit condition, the optimal allocation strategy of the limited irrigation quota in the timing and quantity is proposed. Taking advantage of this system, decision- makers can grasp all kinds of information in crop area, realize the digital, systematic and scientific of the agricultural irrigation resource management, and advance the effective development and sustainable utilization of the agricultural water.

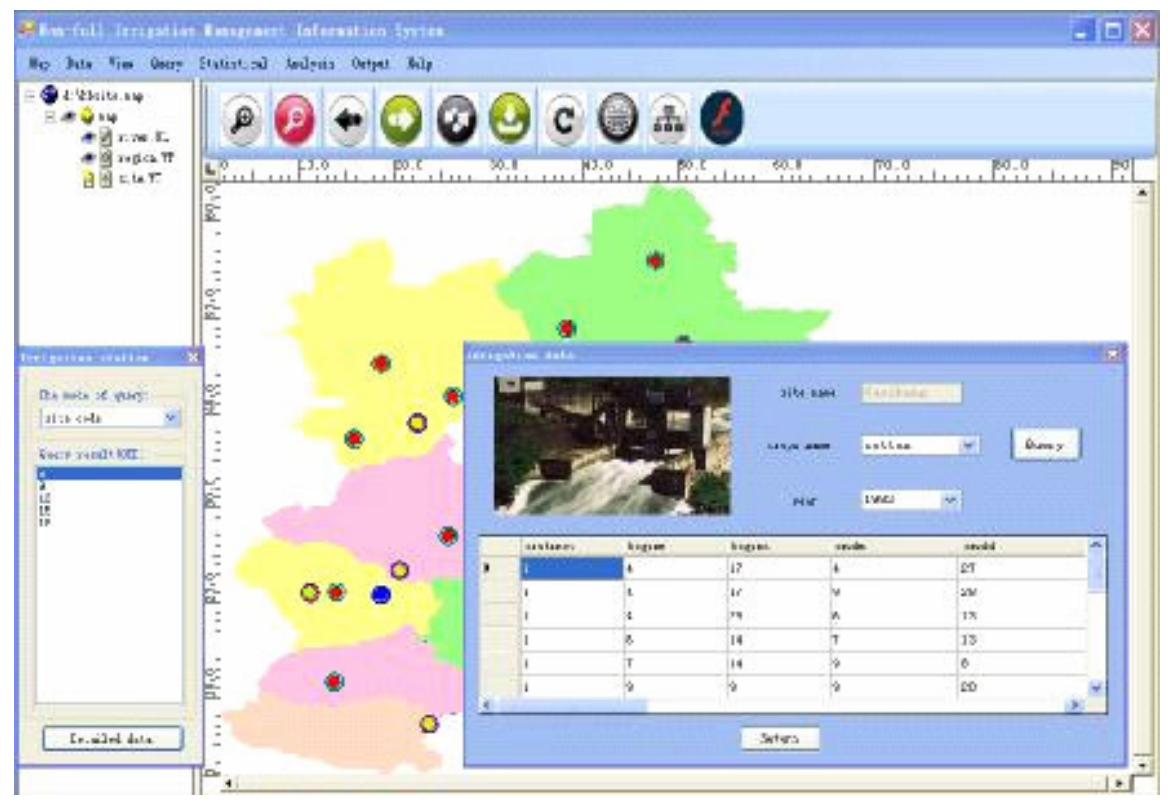

Fig. 2. The partial interface of the system

\section{References}

1. Wang, J.: Utilization and Countermeasures of Water Resources in Hebei Province. Industrial \& Science Tribune 7(2), 85-86 (2008)

2. Liu, C., Zhou, C., Zhang, S.: Study on Water Production Function and Efficiency of Wheat. Geographical Research 24(1), 1-10 (2005)

3. Feng, S., Luo, Z., Zuo, H.: The Study of Water Product Function of Winter Wheat in Hebei Province. Journal of Irrigation and Drainage 24(4), 58-61 (2005) 
4. Yang, L., Xia, H., Wang, F.: Application \& Solution of Jensen Model In Unsufficient Irrigation Schedule. Irrigation and Drainage 21(4), 13-15 (2002)

5. Luo, Z., Feng, S., Zuo, H.: Preliminary Study on Water Production Function for Summer Corn in Hebei Province. Water Saving Irrigation 1, 17-19 (2006)

6. Ge, A., Li, C., Yang, C.: Primary Study on Building Water-saving Agricultural Decision Support System Based on GIS. Remote Sensing Technology and Application 19(5), 392395 (2004) 